\title{
NEOLIBERALISMO E INDIVIDUALIZAÇÃO NAS POLÍTICAS DE SAÚDE NA PERIFERIA SUL DE SÃO PAULO
}

\author{
Ricardo de Lima Jurca *
}

\begin{abstract}
Este artigo tem como objetivo compreender a expansão dos segmentos públicos e privados de saúde no atendimento da população de um território periférico da Zona Sul da cidade de São Paulo. Esta gestão é baseada nas mediações entre o Estado e os usuários dos Serviços Públicos de Saúde. Além dos usuários entrevistados, participaram da pesquisa, dirigentes sociais e agentes do programa de Atenção Primária de Saúde, a Estratégia Saúde da Família (ESF). As questões propostas podem contribuir para identificar e repensar a produção da demanda nas redes sociais dos usuários com acesso aos serviços de saúde públicos e privados na região, e na ampliação da interface da gestão social do programa de saúde com as clínicas médicas populares na periferia de São Paulo. Os relatos mostram a relação dinâmica que existe entre as práticas, ações e a emergência do processo de individualização das políticas de saúde brasileiras.

Palavras-chave: Individualização. Serviços de saúde. Periferia. Neoliberalismo. Saúde pública.
\end{abstract}

\section{INTRODUÇÃO}

Como foi documentado em diferentes trabalhos no caso do Brasil (Oliveira, 2013, 2018; Paoli, 2007), o modelo neoliberal desenvolvido nas últimas décadas neste país enfatizou o papel do mercado e sua dinâmica no funcionamento institucional das políticas públicas, orientando as relações entre os diferentes atores da sociedade e entre esses e o Estado. Tal modelo é usado como referência no campo da saúde. Fato é que o modelo neoliberal ${ }^{1}$ acelera o processo de individualização, que deu lugar às modalidades de gestão de risco indi-

* Universidade de São Paulo. Instituto de Arquitetura e Urbanismo da (IAU-USP)

Av. Trab. São Carlense, 400. Centro. Cep: 13566-590. São Carlos - São Paulo - Brasil. rljurca@usp.br. http://orcid. org/0000-0003-3226-4839.

Agradeço o financiamento da Fundação de Amparo à Pesquisa do Estado de São Paulo (FASESP), através do processo n ${ }^{\circ}$ 2015/16218-0, bem como a bolsa da Coordenação de Aperfeiçoamento de Pessoal de Nível Superior (CAPES) $n^{\circ}$ 2015/1560056.

${ }^{1}$ Como Dardot e Laval (2016) ressaltam uma das características distintivas do modelo neoliberal está relacionada a uma nova construção de assunto que atraia a capacidade de agência, exaltando as dimensões do "esforço individual" e do "empreendedorismo". Em suma, os autores falam sobre "fazer-se uma empresa" e, portanto, administrar suas capacidades e recursos para a conformação de sua própria identidade. vidual e à mobilização de redes sociais para lidar com as contingências diárias. Alguns estudos investigam ainda a influência deste paradigma em termos das relações sociais, referindo-se à acentuação da mercantilização em países como o Chile e Argentina (Aguirre;Valderrama, 2015; Araujo; Martuccelli, 2011; Gago, 2018); ou referindo-se ao empreendedor de si e à aceleração o de processos de privatização e de individualização no Brasil (Rizek, 2016a). De fato, as consequências desses processos foram diferentes nesses países, embora ainda pouco exploradas em termos de acesso e uso dos serviços de saúde na vida cotidiana dos indivíduos.

Particularmente, neste trabalho interessa-nos compreender a expansão dos segmentos públicos e privados para políticas sociais com foco na saúde, para a gestão do território periférico da Zona Sul da cidade de São Paulo, a partir das mediações entre o Estado e os usuários dos serviços públicos de saúde. As formas pelas quais as pessoas constroem os seus vínculos institucionais no cotidiano - por meio de diferentes ações e projetos governamentais, organizações e instituições sociais - afetam as repre- 
sentações que fazem de si mesmas e dos outros, o que, por sua vez, influencia os comportamentos e contribui para a construção de práticas simbólicas de grupos particulares (Martuccelli, 2007; Aguirre; Valderrama, 2015; Rizek, 2016a).

Essas relações, no entanto, dinâmicas e diversificadas, não derivam única e diretamente das instituições: os sujeitos constroem discursos, práticas e argumentações, além do oficial. Considerada essa perspectiva, pode-se dizer que os objetivos ideológicos, técnicos e políticos que apoiam as políticas sociais têm relação e impacto parcial nos indivíduos. O presente artigo apresenta uma análise baseada em pesquisa de campo com o(a)s usuário(a)s de serviços de saúde do setor público e privado da região metropolitana de São Paulo, mais especificamente, da comunidade da favela de Heliópolis.

Os estudos sobre a "gestão do mundo social” foram fundamentais para o desenvolvimento da análise do processo de individualização na periferia de São Paulo (Feltran, 2014; Georges; Santos, 2016; Rizek, 2016a). Esses estudos possibilitaram distinguir os indivíduos: entre aqueles que, como uma bolha, se beneficiam de uma ampla rede de serviços e recursos que lhes servem de apoio, e que lhes transmite, inclusive, um sentimento de despreocupação relativa frente a muitas vicissitudes da vida; e os que, no outro extremo, carecem de suportes dessa rede, e vivem mais expostos tentando construir "diques" ou "escudos" para protegerem-se de um conjun\&ิ to de riscos que percebem onipresentes.

๙ O esquema de intermediação assisten§̊ cial praticado pelo segmento privado de saúde, ¿ em atuação no sistema de saúde brasileiro, será Aี aqui pensado nos moldes do debate sobre as po¿. líticas sociais brasileiras, dedicado à análise das ले ações e gramáticas acionadas entre programas sociais de saúde, ONGS e Organizações Sociais de Saúde ${ }^{2}$ (Rizek, 2013, 2016; Georges; Santos, 2016). No campo dos estudos teóricos acerca

2 Lei no 14.132, de 24 de janeiro de 2006. "As organizações Sociais são pessoas jurídicas de direito privado, sem fins lucrativos, cujas atividades sejam dirigidas à saúde, atendidos os requisitos previstos nessa lei" (Prefeitura de São Paulo, http:// www.prefeitura.sp.gov.br/cidade/secretarias/saude/legislacao/ index.php?p=6196, acessado em 24 de fevereiro de 2019. da produção da Saúde Coletiva, previamente elaborados nos anos 1980, foram essenciais os textos à época para melhor compreender a discussão sobre a especificidade do Estado capitalista brasileiro e a histórica relação entre a saúde privada e a acumulação capitalista no país (Ianni et al, 2017). Destacam-se autores tais como, Sonia Fleury Teixeira $(1989,1992)$, Jaime de Oliveira e Sonia Fleury Teixeira (1986), Jaime de Oliveira (1987) e Braga e De Paula (1981).

Essas análises contribuíram para a compreensão das interconexões entre o financiamento público e o movimento de capitalização da medicina nos anos 1960 e 1970, servindo de material de apoio à construção, pelas políticas de saúde, ${ }^{3}$ das bases do novo sistema que se materializou no Sistema Único de Saúde - SUS (Sestelo, et al, 2017). A inscrição constitucional do SUS $^{4}$ e sua implementação ao longo das últimas três décadas, não foram capazes de conter o aprofundamento da lógica neoliberal no setor saúde. Nesse sentido é possível observar, de forma estrutural, que as reconfigurações dos sistemas universais de saúde e o surgimento de novas necessidades de consumo correspondem às reformas na organização e prestação dos serviços neste setor. O aprofundamento da globalização acompanhado pelo fortalecimento da massificação do consumo, para além do seleto segmento social de maior renda, por exemplo, traz novos elementos para a popularização de um novo paradigma de produção, concentração e financeirização do setor de serviços.

Assim, explorar a natureza das mudanças sociais envolvidas nos processos de individualização e de crise das instituições políticas

${ }^{3} \mathrm{~A}$ época, as políticas de saúde, a rigor, não poderiam ser consideradas como "políticas sociais". A ideia de cidadania relacionada ao direito à saúde não estava posta constitucionalmente. Aliás, a saúde não era direito e sim, um benefício a poucas categorias inseridas no mundo do trabalho formal.

${ }^{4}$ O SUS é, segundo prevê a Lei8.080, um conjunto de ações e serviços de saúde, prestados por órgãos e instituições públicas, federais, estaduais e municipais, da administração direta e indireta e das fundações mantidas pelo Poder Público. Baseado nos artigos 196 ao artigo 200) da Constituição Federal de 1988, o Brasil garantiu à sua população o acesso universal, integral, igualitário e gratuito à saúde por meio de um sistema único e descentralizado. 
modernas é, nesse momento, crucial, pois elas condicionam e determinam a produção da saúde em sentido amplo e no campo da Saúde Pública, em particular. Nessa perspectiva, cresce o interesse pela temática da proteção social, não aquela do sistema de seguridade social, ou da sua sustentabilidade econômico-financeira, etc., "mas o que pode vir a ser proteção social hoje, para pessoas que vivem num contexto de individualização crescente do corpo social em um mundo de inseguranças autoproduzidas, e qual deve ou pode ser o papel da Saúde Pública nesse novo contexto" (Ianni, 2012, p. 170).

\section{A INDIVIDUALIZAÇÃO DAS POLÍ- TICAS SOCIAIS ATRIBUÍDAS AOS PROGRAMAS E SERVIÇOS DE SAÚDE}

A individualização das políticas sociais tem história no Brasil e já redefiniu parte do desenvolvimento das políticas públicas (Cohn, 1996). A atuação dos programas sociais de saúde como o programa Estratégia Saúde da Família $(\mathrm{ESF})^{5}$, é fundamental para a análise deste artigo, em se tratando do desenvolvimento da atenção primária no Brasil, porque, demonstra no cotidiano do acesso aos serviços de saúde, o entrecruzamento das dimensões pública e privada da vida social. Em Heliópolis, quando analisamos as práticas desenvolvidas pelos Agentes Comunitárias de Saúde (ACS), ${ }^{6}$ obser-

${ }^{5}$ O ESF foi integrado ao Sistema Único de Saúde como uma iniciativa que promove a prevenção e a identificação de doenças, assim como a educação sanitária, em contraponto às iniciativas curativas centradas nos hospitais. O ESF tem sido desenvolvido por equipes multidisciplinares que atuam nos bairros dos diversos municípios brasileiros a partir de uma Unidade Básica de Saúde (UBS), cuja missão é prestar localmente serviços e orientações básicas de saúde e, caso necessário, garantir o acesso aos pacientes para as unidades especializadas mais próximas (Ministério da Saúde, 2002).

${ }^{6} \mathrm{O}$ trabalho de gestão dos fluxos realizados pelas ACSs, necessita que elas atribuam um nível de prioridade às demandas, adequando-se à disponibilidade de serviços da equipe. Cada equipe é composta por um médico, um enfermeiro, um auxiliar de enfermagem e cinco agentes comunitários de saúde. A missão de uma ACS é a de atender individualmente cerca de 200 famílias em domicílio. $\mathrm{Na}$ maioria dos casos, aos ACSs bastam o diploma de ensino fundamental para participar de uma seleção para o cargo (Ministério da Saúde, 2001). Desde a Lei Federal no vamos que ainda há uma baixa institucionalização do programa em virtude de sua recente implantação. A atuação dos ACS apresenta certa confusão a respeito de qual deve ser o seu papel e a natureza das suas atividades, ao mesmo tempo em que a Unidade Básica de Saúde $(\mathrm{UBS})^{7}$ ainda está organizando suas rotinas.

Além disso, o trabalho dos ACS na Unidade Básica de Saúde/ UBS Sacomã, em Heliópolis, passou recentemente a ser terceirizado, depois que a Associação Paulista para o Desenvolvimento da Medicina (SPDM), da Universidade Federal de São Paulo, assumiu a gestão da Unidade. Desde essa terceirização, os ACS são contratados por tempo determinado e o profissional é altamente rotativo. Nesse contexto, as informalidades do dispositivo de "ordenamento estatal” ampliam-se e a ação dos ACS, que tem por característica a capilaridade social na comunidade local, a utilização das redes de vizinhança, e o conhecimento do território, é incorporada pela empresa terceirizada ao processo de trabalho da assistência à saúde, na lógica da racionalização do serviço prestado e custo mínimo, ao mesmo tempo em que a política pública de Atenção Primária instala-se com um mínimo de construção social, "terceirizando" a responsabilidade da própria assistência para os indivíduos (Georges; Santos, 2016).

Por exemplo, a forma como os ACS fazem a reprodução e a transmissão da comunicação com o(a)s usuário(a)s é interessante para compreender o processo de privatização e a crescente segmentação do sistema de saúde. Os ACS, que residem na comunidade, têm como função conectar o(a)s usuário(a)s aos serviços públicos. O cara-a-cara no balcão dá lugar a formas cada vez mais singularizadas de

10.507/02, que criou a profissão técnica de ACS, exige-se, formalmente a conclusão de um curso técnico de 400 horas (Lotta, 2008)

${ }^{7}$ Unidades Básicas de Saúde ou UBS é a designação adotada desde 2007 no Brasil por meio do Programa de Aceleracão do Crescimento sendo que tais unidades desempenham as mesmas funções dos antigos Postos de Saúde sendo tal denominação gradativamente substituída por Unidade Básica de Şaúde (Ministério do Planejamento. Unidade Básica de Saúde. http://www.pac.gov.br/infraestrutura-social-e-urbana/ubs-unidade-basica-de-saude. Acessado em 15 de fevereiro de 2019.). 
orientação em situações de acesso aos serviços públicos que regulam as relações entre os usuários, o Estado social e o mercado. A individualização das políticas sociais, nesse sentido, tem sido acompanhada por uma reviravolta que tem consequências para a distribuição dos direitos sociais, neste caso, o acesso à saúde.

Essa é uma das faces da condição histórica que hoje tem o indivíduo, não apenas nos países de capitalismo periférico, mas também nos países centrais. (Rizek, 2016a; Fassin, 2018; Cabanes, 2019). A diferença está na agressividade com que isso ocorre no capitalismo periférico (com a incompletude das políticas em termos de focalização, seletividade, e privatização, de ter de viver sob diversas modalidades de dispositivos sociais distintas dentro de um mesmo sistema de saúde). Existe um embaralhamento das fronteiras entre o sistema público e a esfera privada, no caso de Heliópolis, que pôde ser observado tanto com relação às características particulares da Unidade Básica de Saúde /UBS e a empresa terceirizada, como quanto aos vínculos estabelecidos pelas ACS com a respectiva população atendida.

Segundo Léa Lima (2010), a implementação dessas políticas sociais passa, muitas vezes, pela criação de dispositivos de deliberação coletiva sobre os casos particulares e os indivíduos. A garantia de direitos e a prestação de serviços na ação social estão se afastando cada vez mais de um modelo universalista e ธิ automático para se estabelecer através de proC. cessos complexos de negociação dentro dos fazer" os direitos sociais, excluindo parcela significativa da população do acesso ao direito $\rightarrow$ mediado pela política (drenando-os ao mercaळ do). No grupo focalizado, isto ocorre redepo$\vec{s}$ sitando no indivíduo toda a responsabilidade pela utilização dos serviços de assistência. Ou ainda na ideia de pobreza como nicho de negócios que Rizek (2010, 2012, 2013, 2016ab) explorou em vários textos.

Esses elementos, apresentados de forma resumida, apontam para uma ampliação signi- ficativa da margem de ação das Organizações Sociais de Saúde, como operadoras de um regime de terceirização dos programas sociais de saúde no qual assume a gestão e o recrutamento do pessoal. Endossa, de fato, a nova onda de privatização da saúde por meio das parcerias de gestão dos equipamentos públicos estatais por organizações sociais públicas de direito privado, associadas à falência financeira dos estados e municípios, certamente fazendo com que esse novo procedimento de financiamento se traduza num fator de diferenciação interna do sistema de saúde muito além daquela permitida num sistema público de saúde. Ao abrir espaço para o mercado, expande a margem de ação para uma gama de serviços de saúde privados como, as clínicas médicas populares que chegam a operar "nichos de negócios" no segmento privado com fins lucrativos (laboratórios, clínicas e policlínicas populares). Desta forma, estabelece-se um ramo de atuação, permeado pela exploração da assistência social e à saúde no território por uma falta de oferta induzida, seja pela política nacional (agora com a Portaria $2.979^{8}$ ), seja pela lógica de trabalho operado pela OSS, no qual fica cada vez mais difícil de discernir a atuação do Estado e sua soberania, generalizando o que foi chamado de "mercadoria política" (Misse, 1997). Tanto o controle sobre os fluxos financeiros, como as decisões políticas e o controle dos direitos, no âmbito da forma de concretização destas políticas sociais, se obscurece, e perde a perspectiva da reivindicação de algum direito coletivo, de cunho "universal" (Lautier, 2014).

No fundo, trata-se menos da primazia do estado social sobre a sociedade, e mais sobre a desestabilização protetiva que vai se consolidando como sistema co-produtor do mercado. Quando se observam as facetas do Estado produtor, provedor e/ou regulador, e de como

${ }^{8}$ Institui o Programa Previne Brasil, que estabelece novo modelo de financiamento de cușteio da Atenção Primária à Saúde no âmbito do Sistema Único de Saúde, por meio da alteração da Portaria de Consolidação $n^{\circ} 6 / \mathrm{GM} / \mathrm{MS}$, de 28 de setembro de 2017. Disponível em: https://www.in. gov.br/en/web/dou/-/portaria-n-2.979-de-12-de-novembro-de-2019-227652180. Acesso em 13 de nov. 2020. 
está se criando um sistema híbrido de proteção social, verifica-se o estabelecimento de direitos, semi-direitos ou quase direitos. Neste artigo buscou-se analisar a inserção da assistência médica privada sobre as redes sociais dos moradores da favela de Heliópolis.

\section{O PROJETO SOCIAL E O EMPRE- ENDEDORISMO DE SI NA PERIFE- RIA DE SÃO PAULO}

A sociedade brasileira, com uma intensidade inusitada desde o fim dos anos 80 , foi o teatro exacerbado de um dos grandes conflitos das sociedades modernas, entre a lógica do mercado e a lógica da proteção. Na raiz da constituição de 1988, o país colocou em prática um conjunto de medidas econômicas que progressivamente se converteram no modelo neoliberal (privatização, liberalização econômica, desregulação, abertura internacional, flexibilização do trabalho).

A instauração do modelo neoliberal no país não foi, porém, linear. A natureza e a profundidade da inflexão introduzida nos anos 90 são objetos de constantes discussões. A razão, para além dos aspectos técnicos, é evidente: trata-se não somente de definir a natureza real do modelo a ser implementado, mas também de articulá-lo à implementação democrática (pós-ditadura militar). O modelo neoliberal introduzido no país produziu um redesenho radical das relações sociais entre o mercado e o Estado. As relações entre as classes sociais sofreram uma profunda transformação à medida que a economia nacional se orientou para o mercado de capitais, que passou a regular, sobre novas bases, o mundo do trabalho, transformando os princípios da proteção social e, para além disso, os serviços públicos aos quais os cidadãos pudessem ter acesso.

As investigações sobre políticas de desenvolvimento social na periferia da cidade de São Paulo iluminam essa questão (Kowarick, 1993; Telles, 1994; Santos [1985], 2014). Mais uma vez, aqui, o caso de Heliópolis é exemplar. A atuação das Associações Sociais nessa favela, como a da UNAS (União dos Núcleos das Associações Sociais de Heliópolis), revela novas relações entre sociedade-Estado-mercado. As dimensões pública e privada se fazem presentes nessas Associações Sociais por meio de editais de financiamento, projetos de incentivos variados e terceirizações de serviços públicos. Já não é mais "a periferia excluída" (Kowarick, 1975) que se caracteriza nesse território, mas uma periferia com uma forma específica de classe social precária, em um contexto de individualização marcado pelo consumo e o empreendedorismo de si.

A gestão das políticas e ações sociais aponta para uma inter-setorialidade, conformando um planejamento social privado, particularizado, individualizado. Como descreve Cibele Rizek (2016a, p. 199) a respeito de outra experiência na periferia de São Paulo, trata-se de "um conjunto de planejamentos sociais privados de gestão", que está redesenhando as formas de atuação do Estado na sua relação com programas sociais e com a população paulistana. O empreendedorismo de si assume aqui as características do trabalho informal, como um importante elemento que estrutura a vida social nas periferias da periferia do capitalismo. Não importam as condições de trabalho, o que importa é estar trabalhando. $\mathrm{O}$ olhar mais atento ao cotidiano dessas periferias torna perceptível a forma de precarização do trabalho somada à precarização da proteção social, constituindo um mercado de trabalho marcado pela precariedade.

Precariedade definida pela ausência de elementos comumente considerados importantes como formas de proteção do trabalho, tendo em vista certo grau de estabilidade e segurança financeira, como: décimo terceiro salário, férias, seguro desemprego, ou mesmo, a experiência de registro de trabalho comprovado na carteira. E principalmente, precariedade trazida para a vida como um todo, a partir da naturalização de condições transitórias de trabalho e 
da fragilização da estrutura dos serviços sociais como marca permanente de projetos de vida.

Para Rizek (2016a, p.28), tal mercado de trabalho constrói-se mesclando "trabalho cultural" com "trabalho social" como experimentação de um trabalhador produtivo, por conta própria, em locais afastados de um mercado de trabalho formal. Outra configuração dessa forma de trabalho emerge, no caso de Heliópolis, por meio de agentes, os ACS, colaboradores ${ }^{9}$ de um Estado que vai deixando a cena como responsável pela formulação e execução de políticas sociais: a política pública de saúde. Há uma produção de indivíduos que são, em tese, duplamente público-alvo: dessas oportunidades de trabalho e como agentes das intervenções dos projetos sociais. Isso os torna "criadores de objetos de gestão, acomodação e pacificação" (Rizek, 2016a, p. 211) dos problemas enfrentados no dia a dia pela comunidade. Essa mistura entre trabalhadores autônomos, jovens lideranças e o conjunto de empresas e organizações, vai compondo um "social de dimensão híbrida” (Rizek, 2016a, p. 211) que, em certa medida, pacifica a desigualdade social.

Tal arranjo não se propõe a dirimir a desigualdade social, antes possibilita a coexistência na desigualdade, uma forma social mais alinhada ao nível individual do ideário neoliberal do que ao nível de uma comunidade com potencial e anseio de reivindicação coletiva de direitos em torno de alguma proteção social. के Esse caminho tem sido tudo, menos linear, a tal N. ponto que a implementação dessas ações e práठ̊ ticas engendra resistências diversas, mas não 屯ิ uma resistência pela cidadania. Há resistência न para a sobrevivência. Porém, como veremos, e ¿ aqui está o verdadeiro paradoxo, os indivíduळ os, a partir inclusive de interpretações políticas

$\overrightarrow{~ d i a m e t r a l m e n t e ~ o p o s t a s, ~ c h e g a m ~ a ~ u m a ~ m e s m a ~}$ conclusão: a de se sentirem presos em um siste-

^ ${ }^{9}$ A socióloga Amélia Cohn no artigo "Caminhos da refor"I ma sanitária revisitado" (2018) e no artigo "O jogo de va-

ک retas e a desconstrução da cidadania” (2016), desenvolve

essa expressão bastante utilizada no meio empresarial que passa a ser de uso corrente nas Organizações Sociais de Saúde para denominar o contingente da massa trabalhadora de saúde como colaboradores. ma individualizado de produção da vida.

Ou seja, projeto de vida e formas de trabalho-consumo se entrelaçam em sujeitos neoliberais (Dardot; Laval, 2016), possibilitando uma tênue ascensão social traduzida em status de uma posição diferenciada na comunidade, sem que isso represente mudanças substanciais em sua situação socioeconômica. A própria ideia de liderança, nesses casos, estaria deslocada de um sujeito capaz de mobilizar a comunidade com intuito da reivindicação política para a de um sujeito com potencial criativo que faz a gestão do próprio trabalho-negócio-comunidade. Portanto, pode-se dizer que estariam sendo experimentadas nessas periferias formas de fazer política associadas à responsabilidade social ${ }^{10}$ empresarial (Vasconcelos; Alves; Pesqueux, 2012), captando assim como ativo econômico os bens imateriais ali presentes. A trajetória dos membros da Associação de bairro de Heliópolis, por dentro dos projetos sociais, expõe uma política social que faz parte da construção do indivíduo como um produtor-consumidor, e apresenta-se como uma questão importante da inclusão social contemporânea por meio das trocas de mercadorias. Isso se soma à concepção do eu como capital de si mesmo. A tal ponto que

o resultado é uma forma nova e crescentemente abstrata de dominação, que sujeita as pessoas a imperativos e coerções estruturais impessoais que não podem ser adequadamente compreendidos em termos de dominação concreta (por exemplo, dominação pessoal ou de grupo), que também gera uma dinâmica histórica contínua. (Postone, 2014, p. 18)

${ }^{10}$ Agir de maneira socialmente responsável tornou-se um nicho de mercado que pode ser atraente para algumas empresas em parcerias com coletivos na periferia. Setores como artesanato, design, moda, filme e vídeo, música, artes performáticas, software, computadores e videogames estimulam a criatividade e a criação de novos coletivos e grupos por "indústrias criativas" voltadas para ampliação do consumo de serviços e bens (Rizek, 2016a).Neste sentido, é possível refletir sobre uma reconfiguração dos serviços de saúde garantindo às empresas do mercado de saúde, maior liberdade para ações próprias ou por meio de seus agentes intermediários, maior poder para influenciar a definição das agendas políticas da sociedade. O fenômeno da emergência das clínicas de baixo custo, por exemplo, tem como estratégia de penetração nos nichos de seu mercado potencial em espaços da periferia das cidades, por exemplo, trazer para junto de si trabalhadores do SUS e lideranças da comunidade para capturarem esse mercado (Jurca, 2018). 


\section{METODOLOGIA}

As questões anteriores se baseiam nos resultados do estudo Individualização social, assistência médica privada e consumo na periferia de São Paulo. A pesquisa foi amparada empiricamente em trabalho de campo multi-situado (Marcus, 2011) com o mapeamento das interfaces públicas e privadas da assistência à saúde no cotidiano das políticas sociais, tomando como ancoragem a política de saúde, assim como as redes que se estabelecem a partir de seus equipamentos e práticas de gestão. Para tanto, procurou-se aprofundar a pesquisa empírica sobre a política social de saúde, com vistas a estabelecer nexos entre os movimentos que ampliaram a sua gestão individualizada na Zona Sul da cidade de São Paulo com o segmento privado de saúde. A seleção da região se deveu à influência desse território no exame da estrutura da assistência à saúde e da mobilidade social das famílias que marcou a trajetória da metrópole nos últimos vinte anos (Marques; Barbosa; Prates, 2015). Aparentemente, a região metropolitana de São Paulo vivenciou algo que pode ser denominado de "profissionalização" que possibilitou a entrada de novos profissionais na região metropolitana, como os médicos. Além disso, o território é coberto e equipado por serviços públicos do Sistema Único de Saúde, como Hospital e Unidades Básicas de Saúde e por grupos de empresas de planos privados, laboratórios de diagnósticos e clínicas médicas populares da esfera privada da saúde. Assim, a escolha por centrar a análise na Organização Social de Saúde de Heliópolis e o programa Estratégia Saúde da Família e seus cruzamentos com serviços de saúde da esfera privada, está ligada ao fato de um conjunto desses equipamentos de saúde se constituir de maneira muito central pelos nexos da assistência médica privada, acompanhando e se adequando às transformações das políticas sociais e econômicas importantes, bem como por se inserir de modo bastante capilar em espaços classificados como socialmente vulneráveis e problemáticos na Zona Sul. O que contribui muito na explicação das relações que propomos discutir no cotidiano do território.

Dado que os contatos na gestão dos equipamentos e programas de saúde da Atenção Primária foram os pontos de partida desta pesquisa, foram programadas, em Heliópolis, algumas imersões de trabalho de campo periódicas: i) entre fevereiro e junho de 2016 e; ii) entre agosto e novembro de 2016 (8 meses no território). As estratégias mobilizadas nas incursões a campo, a partir do acompanhamento das rotinas e conexões da Unidade Básica de Saúde - Sacomã, com a Organização Social de Heliópolis, ${ }^{11}$ se deram a partir do seguinte conjunto de práticas empíricas e analíticas: i) retomada das incursões aos territórios, que acessamos em 2015, realizando conversas com interlocutores conectados aos circuitos da Estratégia Saúde da Família, e com os quais já possuímos relação de confiança e pesquisa, registrando os achados em diários de campo; ii) recuperação sistemática de cada trecho de diário de campo, entrevista ou situação vivenciada junto ao atores inscritos no cotidiano das UBSs; iii) reconstituição analítica dos percursos trilhados por usuários, agentes de saúde e associação de bairro como a UNAS (União dos Núcleos das Associações Sociais de Heliópolis), nas distintas direções que tomaram ao longo da rede social dos entrevistados, assim como de agentes da Organização Social SPDM (Associação Paulista para o Desenvolvimento da Medicina), e usuários que a seus modos se conectam no circuito.

O foco da pesquisa de campo se manteve, portanto, nos espaços institucionais que interconectados, compõem o emaranhado no qual se insere a relação de parceria entre Organização Social, assistência média privada

${ }^{11}$ A ação da OS tem por base a portaria n.498/2008, que institui as ações de saúde destinadas a garantir condições de bem-estar físico, mental e social. Menciona como objetivo "instituir a plena integralidade do cuidado físico e mental aos usuários do SUS por intermédio da qualificação e complementaridade do trabalho das Equipes de Saúde da Família”. Disponível em: https://www.spdm.org.br. 
e as parcerias com clínicas, policlínicas e laboratórios populares. Mas não só, a pesquisa também visou explorar trajetórias, dimensões e relações, bem como redes que se estabeleçam a partir desse objeto. Com efeito, postula-se que, a meio caminho entre as abordagens unidirecionais que pautam suas explicações exclusivamente sobre ações de governo ou sobre teorias de livre mercado, há um espaço de investigação complexo e multicausal a ser explorado, entre prestadoras, e intermediadoras de serviços de saúde. O acesso e uso dos serviços de saúde aumentou sensivelmente nos últimos 20 anos, com destaque para as unidades de atenção primária e a Estratégia Saúde da Família (ESF). Considera-se aqui, que os indicadores de acesso aos serviços procuram informar sobre um padrão de uso contínuo ou habitual pelos entrevistados, e de forma combinada, já que existe a possibilidade do acesso e uso de equipamentos privados de saúde ter sido feito por mais de uma fonte (via SUS, desembolso e cobertura pelo plano de saúde, por exemplo).

A pesquisa bibliográfica e documental teve como ponto de partida a bibliografia teórica que embasa a abordagem aqui proposta articulada a etnografia do Estado (Das; Poole, 2004), com os processos de financeirização do cotidiano (Gago, 2018), tomando como dado as políticas sociais brasileiras (Georges; Santos, 2016; Rizek, 2016a). Assim, como Gago (2018), parece-nos que, sem questionar os modos em సิ que a inclusão se produziu no Brasil através N dos dispositivos financeiros, e em particular, da articulação entre subsídios estatal e endividaชิ mento para consumo, não dimensionamos por 今- completo o modo de "desenvolvimento" que se ¿. postulou na última década, inerente a uma artiભ culação com o mercado global e aos padrões de $\therefore$ consumo que nos impuseram. Segundo Gago (2018), isso significa que as finanças se tornam um código que consegue homogeneizar essa pluralidade de atividades de mercado, fontes de renda, expectativas e temporalidades.

A elaboração do sociograma (Figura 1) parte da extração de minha experiência em campo e das entrevistas realizadas no período. Tal elaboração se deu a partir da triagem preliminar do material produzido e acessado em campo - diários de campo e transcrições de entrevistas; passando pela análise intensiva e definição das dimensões centrais no roteiro de entrevistas, relevantes à pesquisa; e seguiu na direção da elaboração das esferas sociais (no caso aqui estudado usuários, ACS, UBS, Associações), partindo do exame minucioso do material selecionado, e de sua ordenação por conteúdo e padrão com base nas atividades inseridas no contexto da pesquisa para retratar as relações sociais que, na dinâmica local, são operativas na definição de distinções e conformações de práticas. Este procedimento abriu a possibilidade de recorrer à teoria e as análises relevantes dos campos com os quais este trabalho dialogou para experimentar a relação dos grupos sociais de modo indutivo a partir da pesquisa de campo com os atores mobilizados na rede social estudada.

Nesse sentido, os fatores relacionais explorados nas entrevistas são importantes, porque expressaram a centralidade do Agente Comunitário de Saúde (ACS) na rede social, a partir das diferentes afiliações dos atores na gestão dos serviços de saúde, que eram ocultas dentro de concepções sistêmicas totalizantes. Mais especificamente, o estudo permite pensar os usuários, nas margens da rede social, cujo acesso aos serviços de saúde define a zona híbrida entre o mercado e o Estado, e como esses indivíduos situam-se na interface pública e privada da gestão social da saúde. Trata-se de mostrar, em grande angular, como na experiência cotidiana da população, dos profissionais de saúde e dirigentes sociais, as políticas e as instituições públicas são atravessadas pelas trajetórias do(a)s usuário(a)s. ${ }^{12}$

\footnotetext{
${ }^{12}$ Todos os nomes citados são fictícios. Foi elaborado o "Termo de Consentimento Livre e Esclarecido" (TCLE) (Anexo III), utilizando-se de uma linguagem clara e objetiva, por meio do qual os sujeitos foram informados sobre os objetivos do estudo, os procedimentos de coleta de dados, possíveis constrangimentos ou benefícios, sendo garantido o sigilo e respeitado o desejo ou não de participar.
} 
Figura 1- Sociograma de Heliópolis

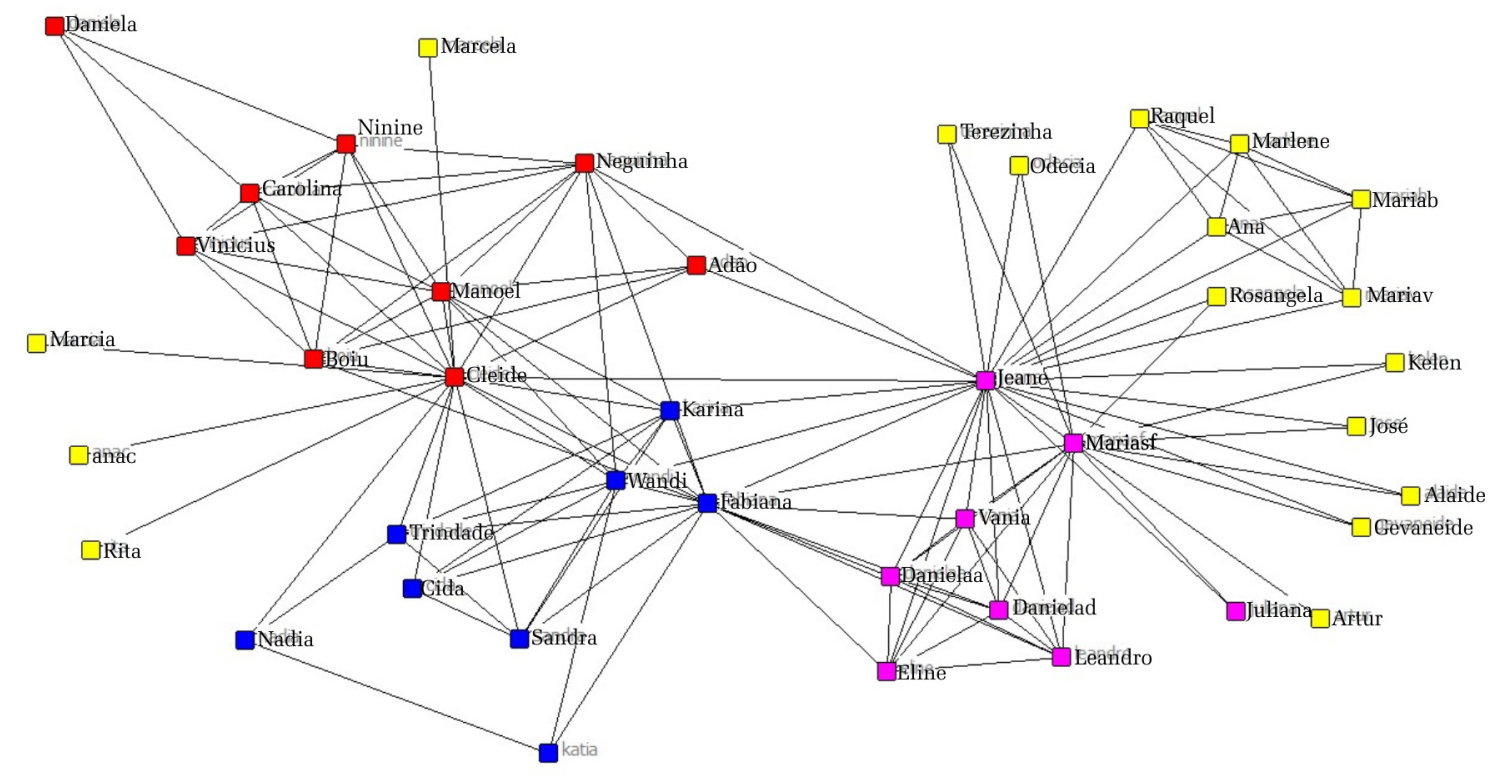

Fonte: Elaboração do Autor (2018).

Esclarecemos que o roteiro de entrevistas utilizado continha perguntas sobre a trajetória de vida e profissional do/a entrevistado/a, além de quatro dimensões de questionamentos:

- Resultados das recentes mudanças nas relações sociais da favela de Heliópolis: onde se buscou captar os significados das experiências vividas pelos moradores no dia a dia.

- Relação com outros agentes da comunidade: onde se indagou sobre as relações entre Associações locais, governo e mercado, na produção do acesso à assistência médica.

- Recursos materiais e imateriais: onde se indagou sobre os recursos econômicos ou de informação utilizados na rede de relações sociais para o acesso às redes de saúde pública ou privada.

- Relação com a expansão do mercado na favela, incluindo as empresas de saúde: onde se buscou a caracterização, definição e valores atribuídos ao acesso às clínicas, policlínicas e laboratórios de saúde nos últimos anos.

\section{RESULTADOS E DISCUSSÃO}

A disseminação do mercado de consumo acompanhando a ascensão econômica para as classes pobres de Heliópolis e a vinda de grandes empresas de fora para a favela, impulsionaram a acessibilidade e ampliação do mercado local. As consequências foram o aumento do trabalho formal e informal, o aumento real do poder de compra, a facilitação do crédito e o consequente endividamento. Nesse sentido, o discurso empreendedor serve como uma luva para a gestão local, que tem na ascensão social dos indivíduos a sua chance de se formalizar nos "novos territórios produzidos" (Rizek, 2012). As interfaces entre os serviços púbicos e privados de saúde estão, muitas vezes, diluídas no cotidiano das relações sociais de Heliópolis, e entre tantas outras práticas sociais cotidianas que organizam o espaço social da favela, duas delas chamaram a atenção durante a pesquisa de campo: as Associações de Moradores, e os Agentes Comunitárias de Saúde (ACS), que ficam no epicentro dessas práticas sociais. As fronteiras permeáveis entre público e privado, aqui, estão relacionadas 
aos estreitos laços entre os indivíduos pertencentes a esses dois grupos.

O padrão de conectividade existente na rede de Heliópolis pode ser caracterizado como de centralidade (denominado estrelas), onde os pontos descentralizados são de máxima dependência do ponto central. Os intermediários dessa rede são principalmente os ACS, o que indica o controle potencial que esses indivíduos podem exercer. As Agentes Comunitárias de Saúde (ACS) exercem o papel de "porteiras" da rede social e indicam aos usuário(a)s das políticas públicas de saúde o uso complementar de clínicas médicas particulares na região, tomando a relação existente entre a estrutura de relações dos indivíduos, as dimensões das mudanças das relações materiais e imateriais, das relações com as associações sociais, a expansão das empresas de saúde na favela. Assim, a primeira fase da pesquisa revelou que as redes sociais dos moradores da favela de Heliópolis eram densas e centralizadas. Eram redes muito locais, com variabilidade de sociabilidade, mas baseadas, sobretudo, em relações de vizinhança e família.

Em uma segunda fase, a partir da análise das práticas e discursos de uma forma de inserção dos usuários do sistema público na assistência médica privada, por meio, das quatro dimensões destacadas acima na descrição dos métodos, foi possível revelar a natureza da relação entre os indivíduos e as mudanças so\&ิ ciais contemporâneas. No caso de Heliópolis, a - situação produz um indivíduo que tem que se \%े responsabilizar por si mesmo. Para este indiví¿ duo não se trata essencialmente de "escolha" 吉 ou “decisão", mas de "fazer".

$\dot{2} \quad$ A dimensão das recentes mudanças nas ले relações sociais em Heliópolis, como afirma

Carolina, dirigente social, que observa:

O que eu digo, individualizado, é na questão de lutas, sabe?. Que o pessoal acha que eu tenho um emprego garantido, eu não preciso me preocupar com o meu vizinho que está desempregado ou as reformas trabalhistas que tipo... a gente fez projeto social né, participou de projeto na adolescência... eu venho desde a... eu participo de projetos desse tipo desde os dez anos (Entrevista realizada em 06 de agosto de 2016).

Na busca pela proteção social, seja na esfera pública ou privada, o indivíduo tem que enfrentar desafios estruturais de um conjunto de representações institucionais centrais que, mesmo desreguladas pelo mercado, o obriga a constituir-se como sujeito. O indivíduo em Heliópolis é chamado, o tempo todo, para regimes normativos de "proteção social", tão diversos quanto a sua autolimitação, autocuidado, sobrevivência material. Não nos referimos, aqui, à autoestima psíquica, senão a uma forma peculiar de confiança nas capacidades práticas de cada um, em habilidades que eles têm para lidar com as situações. O indivíduo se torna uma fonte de segurança pragmática em meio a uma sociedade percebida como fonte permanente de insegurança. A confiança em si mesmo é um princípio para enfrentar a vida, uma habilidade e um instrumento, mais que um estado cognitivo. O indivíduo se constrói, desta forma, em sua capacidade de fazer. Inclusive, quando critica as instituições, não o faz necessariamente em uma posição de espera daquilo que poderiam, ou deveriam, lhe oferecer as instituições, algum serviço, assistência, etc. As instituições, nesse contexto, são um recurso a mais a serem mobilizados pragmaticamente e pontualmente, e não o eixo de apoio do indivíduo para o enfrentamento dos desafios que lhe são apresentados.

Quanto à dimensão da relação com as associações, em Heliópolis foi possível conhecer o trabalho das jovens dirigentes sociais Ninine e Carolina que coordenam o projeto "Facebook na Comunidade" da Associação dos Moradores UNAS. Sobre esse projeto social, que desenvolve o empreendedorismo em Heliópolis, a dirigente Carolina afirma:

Aqui no laboratório a gente dá aula, né. Eu e os meninos a gente dá aula. Quando a gente não dá aula no laboratório a gente tá procurando novos clientes. Pessoas dentro de Heliópolis que queiram aderir ao projeto. A gente atende o comércio, só se 
for dentro de Heliópolis, até São João Clímaco, mais ou menos.

Fora disso aí... Porque assim, o objetivo do projeto é tornar Heliópolis um bairro empreendedor, né. E aí a gente expandiu o projeto, porque a gente viu que tinha muita procura das pessoas lá fora. Só que esse atendimento nosso se limita ir até os comerciantes de Heliópolis (Entrevista realizada em 05 de Junho de 2016).

A outra dirigente social, Ninine, traz um relato sobre o desenvolvimento de um aplicativo de saúde para a comunidade:

A ideia do laboratório aqui dentro de Heliópolis, desde 2015, sempre foi a gente trabalhar a questão primeiro do empreendedor. De capacitar ele, de ensinar como usar uma ferramenta, que comunica pro mundo inteiro sobre o produto de um serviço que ele faz. Esse era um primeiro momento. Durante o meio do projeto, surgiu a ideia de a gente oferecer um curso de aplicativo pra comunidade. De fazer um curso de programação. De chamar os jovens que tivessem interesse, e até os empreendedores, de criarem um aplicativo que fosse aqui pra dentro. Aí nessa fase do projeto, a ideia era que se formassem grupos e que eles tivessem uma ideia de um aplicativo que beneficiasse a comunidade, que de alguma forma fizesse a comunidade crescer. Eles pegaram o tema de saúde e falaram no dia da apresentação que pra eles era muito importante, porque hoje tá um caos, você não sabe onde tem especialista, você não sabe onde você consegue encontrar remédio, você não sabe que horas ele [o médico] tá. Você não consegue agendar direito. E aí eles falaram vamos criar um aplicativo nesse sentido. E eles apresentaram com vontade, correram atrás, porque queriam que esse programa fosse desenvolvido. Tanto que tá no Google Play (Entrevista realizada em 26 de Janeiro de 2016).

Desta forma, reconfiguram-se as dimensões cotidianas, as práticas de consumo, as formas de sociabilidade e as formas de expressões dessas populações. Destaca-se ainda a dimensão das relações imateriais para o acesso aos serviços de saúde: os recursos de informação utilizados na rede de relações sociais para o acesso às redes de saúde pública ou privada tiveram as agentes comunitárias de saúde como principais informantes da rede. A ACS Maria SF, comenta uma pesquisa que fez para um paciente que precisava de uma ultrassonografia.
O paciente é usuário do sistema público pertencente à favela de Heliópolis. "Fiz a pesquisa porque eu tenho os contatos". "Liguei e achei de R\$ 100 por R\$ 78 no Dr. Consulta” [clínica médica popular]. (Entrevista realizada em 10 de março de 2016). Assim, a ACS cita os laboratórios privados que pesquisou. São eles: Lavoisier, Dr. Consulta, Ghuelfond Diagnósticos. Outro paciente dela conseguiu achar sessões de R \$ 80,00 no Hospital Ipiranga, e de R\$ 30,00 em São Caetano.

Conversando com a ACS ela acha que as clínicas populares (setor privado)

...acabam ajudando o posto de saúde [ou UBS]. É comum ter pacientes aguardando uma consulta com o exame do Dr. Consulta. As clínicas de baixo custo ajudam a continuar o tratamento no Posto Saúde. Porque o posto marca consulta muito tempo depois, ou às vezes, ele marca uma consulta e se o exame não estiver pronto você tem que remarcar e aí demora mais ainda" (Entrevista realizada em 22 de junho de 2016).

A área de abrangência da equipe de Maria SF e Jeane está entre a UBS e a Avenida principal do bairro, onde ficam localizados os serviços privados de saúde, como a clínica médica popular. A população atendida pela ACS tem perfil socioeconômico misto, aquele característico das áreas atendidas pelo ESF, que reside em áreas de ocupação ou favelas, e uma população pertencente a um nível socioeconômico diferenciado, um pouco mais alto.

Em outra dimensão, a expansão do mercado de empresas de saúde na favela, indica que as práticas dos usuário(a)s no sistema público passam a utilizar a rede privada de assistência médica com créditos financeiros próprios e muitas vezes em crises socioeconômicas. Por exemplo, Maria V, usuária do Sistema Único de Saúde, faz um relato sobre o seu orçamento para os exames médicos em clínicas populares para dar continuidade ao tratamento no sistema público.

Aí você leva dois, três anos pra conseguir fazer o exame pelo SUS. Então, ele vai no Posto de Saúde [UBS], passa no médico, aí o médico faz o pedido do exame. Então, é muito mais barato e tem a outra 
vantagem, ele passa no 'Dr. Consulta', faz o exame, pega o resultado e volta no SUS. Porque marcar consulta no SUS é fácil, o difícil é exame. Agora se uma pessoa ou médico faz a consulta e fala no diagnóstico que a pessoa está com câncer, aí não pode falar que tem que fazer o exame. Ele corre no Dr. Consulta faz o exame, na mesma semana ele traz o resultado, passa no médico. Então o médico do Posto pode fazer o tratamento dele porque ele [usuário] pegou o resultado do exame rápido. Agora se ele [usuário] fosse esperar o Posto conseguir marcar o exame pra ele [usuário], ia levar uns três, quatro meses. Ele poderia perder a chance de curar. Essa é uma forma" (Entrevista realizada com Maria V em 02 de março de 2016).

Alaíde diz que a última bateria de exames foi paga em seis parcelas.

\footnotetext{
"Paguei a última parcela agora no valor de $\mathrm{R} \$ 238$. A médica diz assim, eu tô vendo uma manchinha aqui. Você fica desesperada. Paga R\$ 90 pela consulta e depois fica preocupada e paga mais tanto para os exames para ver o que é a manchinha. Fui em outra clínica e o médico tirou essa paranóia da minha cabeça. Avisei uma amiga que recebeu o mesmo alerta da médica do Dr. Consulta e se negou a fazer os exames e pagar mais ainda (Entrevista realizada em 11 de fevereiro de, 2016).
}

Alaíde tinha plano privado de saúde, mas hoje em dia busca alternativas fora da assistência médica suplementar. Toma remédio há seis anos. "Eu não paro porque tenho recaídas" (Entrevista em 11 de fevereiro de 2016).

Outra moradora, Kelen, diz que "fez todos os exames de imagem, transvaginal, Pa๙ิ के particular. Foi quando descobriu que tinha pedra na vesícula, os gastos com a saúde aumentaram e ficou endividada. O mal do "postinho İ [UBS] é que encaminha para longe" (Entrevista $\dot{2}$ em 17 de junho de 2016). A renda da família é ल de pouco mais de R\$2000. Ela mostra a guia i do SUS e diz que sem a guia entregue pelas ACS não consegue fazer exames na clínica médica particular a preços populares. Portanto, para o(a)s usuário(a)s, a consequência dessa realidade os convida a tecer redes sociais para protegerem-se dos riscos. Por outro lado, frente aos limites dessas redes, e dado o caráter estrutural, plural e permanente dos riscos, se reforça o sentimento de que, na vida, "você tem que cuidar das coisas sozinho". Os indivíduos se percebem obrigados a buscar respostas por si mesmos a uma série de ruínas estruturais, o que, inevitavelmente, aumenta as suas inseguranças, e entre si.

A indefinição das fronteiras entre política pública e esfera privada pôde ser observada tanto no que se refere às características das respectivas áreas de abrangência, entre as UBS e os serviços privados de saúde (farmácias, clínicas, laboratórios de diagnóstico). Neste cenário híbrido, não muito claro, de uma junção inédita entre o reconhecimento da demanda social, as políticas sociais e o mercado, provocam uma transformação das políticas sociais em negócios no cotidiano da periferia de São Paulo. Segundo Rizek (2016a), é possível que essas práticas possam ser compreendidas como parte dos novos expedientes, dispositivos e arranjos de trabalho que marcam conformações e agentes de um conjunto de programas que permitem cruzar a formulação e a operação de políticas com as práticas e equipamentos que abundantemente grassam pelas periferias em meio aos novos hábitos de consumo, reconfigurações das relações sociais, entre todos esses programas e um conjunto de mercados de várias conformações.

O exemplo do Programa Saúde da Família/PSF, uma vez implantado em São Paulo, levou o setor público a prestar serviços crescentemente vinculados às Organizações Sociais e ao mesmo tempo com uma multiplicidade de programas sociais que estão atrelados à renda (Benefício de Prestação Continuada, Bolsa Família, Renda Brasil, Aposentadoria Rural). O que indica que há vasos comunicantes importantes "de forma que é preciso ver o que há de Estado no mercado e também o que há de mercado no Estado". ${ }^{13}$ Identifica-se nesse proces-

${ }^{13}$ Em entrevista Cibele Rizek comenta: "Nas pesquisas que nós fizemos na periferia fica claro que cada política criva um mercado ou ampliava as margens de mercado. De certa maneira, junto com o bolsa família chegavam as Casa 
so, o fenômeno da emergência das clínicas de baixo custo como estratégia de penetração nos nichos de trabalhadores do SUS e lideranças da comunidade para capturarem esse mercado que se articula com novos modos de privatização, com vasos comunicantes entre o sistema público, geridos por OSs e as clínicas privadas vinculadas ao capital estrangeiro e ao setor complementar dos planos privados saúde. ${ }^{14}$ Interessante notar que nas áreas periféricas, elas se instalam somente após a abertura nos locais de agências bancárias e postos de agências de cartão de crédito. Sobretudo, porque aqui a proximidade com serviços e formas de inclusão financeira (e consequente endividamento) pode reconfigurar as territorialidades periféricas dos programas sociais, dos serviços públicos e sua sobreposição. Assim, por hipótese, o mecanismo que acaba por imbricar serviços públicos e processos de financeirização, vinculado às novas formas de acumulação, se estende e se capilariza tanto nas esferas da vida pública como na vida cotidiana. Segundo Lavinas (2015), a grande arquitetura começa com a criação do crédito consignado, em 2003, que vai vincular acesso prioritário a linhas de crédito com taxas de juros menos extorsivas para funcionários públicos e assalariados formalizados. Em 2004, é estendido aos aposentados e pensionistas. A política social torna-se, em

Bahia, Magazine Luiza e para a minha absoluta surpresa, entre as igrejas das teologias da prosperidade, uma Smart Fit monstruosa. Acho que a maior Smart Fit está em Cidade Tiradentes. Você tem o mercado acoplado as políticas públicas. Então essa binaridade estado mercado que marcou a minha geração das ciências sociais e que precisa ser deslocada. A Evelina Dagnino fala no começo dos anos 2000 de uma confluência perversa. Essa perversidade foi uma palavra utilizada não no sentido da Evelina mas sim no sentido dos vasos comunicantes muito poderosos entre o que há de estado no mercado e o que há de marcado no estado. Acho que a gente precisa pensar nisso. Essa articulação perversa e paradoxal talvez seja resultado de formas estruturantes dos modos de sociabilidade no Brasil. Talvez isso seja menos circunstancial e muito mais estruturante do que circunstancial e a gente precisa deslocar as nossas lentes de análise, porque com a binaridade estado mercado a gente não vê. Ou com uma suposta binaridade Estado sociedade civil a gente não vê" (Rizek, 2016b; Jurca, 2019). Ver em: https:// www.revistaaskesis.ufscar.br/index.php/askesis

${ }^{14}$ Segundo dados do SIOPS (Ministério da Saúde) e ANS, entre 2013 e 2019, os gastos com os planos cresceram $40 \%$ em termos reais, enquanto os recursos do SUS aumentaram pouco mais de $5 \%$, o que resultou numa queda da despesa per capita do sistema público de $2 \%$. particular no caso dos titulares de benefícios previdenciários, o colateral que faltava e que é garantido pelo Estado para além da renda do trabalho, esta, sim, um colateral relevante.

Em paralelo, também em 2004, foi regulamentado o Bolsa Família, que vem, já com atraso, expandir a incorporação, sempre parcial e precária, ao mercado de milhões de famílias cujo grau de destituição não apenas restringia oportunidades, mas ameaçava sua existência e sua dignidade. Pouco a pouco, ampliam-se mecanismos de acesso ao crédito de consumo também aos beneficiários do grande programa nacional de combate à pobreza, para incentivar um modelo de consumo que vem, finalmente, aquecer o mercado doméstico, dobrando as vendas no varejo entre 2003-2014 (Lavinas, 2017).

O usuário dos serviços públicos se percebe, e é constrangido a se perceber, como um elo entre o Estado e o mercado, um produtor e ao mesmo tempo consumidor. É neste sistema de produção de si que a sua possibilidade de enfrentar um terreno de práticas cruzadas na busca pelo acesso à saúde em meio às formas sociais líquidas e transitórias, é colocada à prova. Eles acabam dizendo, se somos indivíduos individualizados é porque existe uma profunda acentuação dos novos perfis individuais a partir das instituições. E temos como indivíduos que aprender a responder as prescrições das instituições, que passam a demandar cada vez mais do indivíduo soluções biográficas para contradições sistêmicas.

Como revelam as entrevistas, em Heliópolis, o indivíduo aparece antes de tudo como alguém que gerencia e se autogerencia, no contexto do mercado e das políticas sociais. Nessa perspectiva, os objetivos ideológicos, técnicos e políticos que apóiam as políticas sociais de saúde das últimas décadas têm tido um impacto importante e particular nos indivíduos das periferias metropolitanas, pois elas contribuem para uma inconsistência posicional desses indivíduos; e sua posição nas redes relacionais não é estabelecida definitivamente, é fluida. Assim, 
o quadro apresentado é ainda muito preliminar, e uma compreensão mais geral das transformações em curso na direção da expansão de rede privada que reduz o SUS a uma espécie de resseguro das operações privadas nas últimas décadas precisa de uma análise estrutural mais aprofundada. Frente aos limites destas redes, e dado o caráter estrutural, plural e permanente dos riscos, reforça-se o sentimento de que, na vida, "você tem que cuidar das coisas sozinho". Os indivíduos se percebem obrigados a buscar respostas, por si mesmos, a uma série de ruínas estruturais, o que, inevitavelmente, aumenta as suas inseguranças no cotidiano.

\section{CONCLUSÕES}

Analisando os relatos dos indivíduos envolvidos na teia das políticas sociais e econômicas e do mercado em Heliópolis, buscou-se identificar o processo de individualização por meio do acesso aos serviços públicos e privados de saúde. Nesta lógica, cabe ao indivíduo, constantemente, em particular no contexto de crise socioeconômica, preencher as lacunas de acesso aos serviços de saúde ou substituí-las. O público e o privado se mesclam na rede autoconstruída. Isso fica mais evidente dada a inconsistência posicional desse indivíduo. Ele é obrigado a enfrentar diversas contingências de maneira bastante pessoసิ al, mesmo quando recorre a certos repertórios institucionais ou redes sociais já conhecidos e \%ั estabelecidos. Em outras palavras, as ações realizadas pelos indivíduos, sejam elas nas redes sociais ou nos casos de natureza institucional, ¿. são ações que carregam uma rejeição: o que é ભ valorizado é o confronto individual, e acima

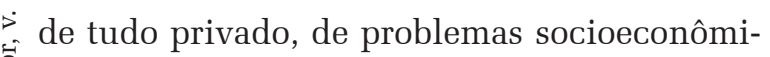
cos ou de saúde.

Desta forma, observa-se, por um lado, um conjunto de aspectos que valorizam o indivíduo empreendedor de si, produzindo um desprezo progressivo pelo ordenamento normativo estabelecido pelo SUS. Cresce o sig- nificado de controle social associado à gestão privada da vida por meio de políticas sociais neoliberais. E, por outro lado, há uma desconfiança em relação ao coletivo e aos "outros" em geral. No fundo, mais do que um individualismo institucional, o que se observa é um processo de individualização social. O indivíduo que aí se produz é um indivíduo relacional, como vimos por diferentes perspectivas (ascensão social, inconsistência posicional, a centralidade das redes de influência, o trabalho e o consumo), e a dimensão relacional é vivida como um recurso básico, embora submetida a fortes tensões e contradições. O indivíduo se percebe, e é constrangido a se perceber, como um elo relacional, um produtor de relacionamentos. É neste sistema de produção de si que a sua possibilidade social é desempenhada: desvendar situações assimétricas de poder, enfrentar os labirintos e caprichos das instituições e buscar oportunidades em meio às formas sociais líquidas e transitórias.

Assim a inscrição constitucional do SUS e sua implementação, ao longo das últimas três décadas, não foram capazes de conter o aprofundamento da lógica neoliberal no setor saúde. O estudo exploratório evoca, assim, caminhos de pesquisa que tornariam possível qualificar as transformações nas políticas sociais. Os estudos no campo da Saúde Coletiva sobre o desenvolvimento capitalista na saúde, contudo, não acompanharam seu movimento, havendo imprecisões e lacunas quanto à caracterização do fenômeno. As possíveis linhas de pesquisa sobre saúde e desenvolvimento, sobretudo, a partir da primeira década de 2000 , pode vir a desenvolver o possível movimento dos diversos segmentos empresariais da saúde em direção a um padrão de acumulação mais associado à financeirização. O aprofundamento desse processo pode ser identificado na expansão da financeirização popular, por parte das empresas de cartões pré-pagos que direcionam ações financeiras do mercado para áreas como saúde, estética, educação e lazer, às famílias de menor renda. Constituem uma 
precária rede de sujeitos endividados, através do acesso ao crédito com taxas de juros relativamente mais baixas e a prazos maiores.

De modo recorrente, já em 2016, foram aparecendo nas narrativas pessoais e familiares, às quais tivemos acesso ao longo da pesquisa, que os setores populares buscam estratégias de acesso aos serviços de saúde mediante a compra de um cartão pré-pago em uma dessas clínicas privadas. Na prática, desconhecem qual a real cobertura a que terão direito em caso de necessidade. Pelo menos 8 milhões de brasileiros já são usuários de cartões pré-pagos para atendimento em clínicas médicas populares, segundo levantamento feito pelo jornal Estado de São Paulo. Para fins de comparação, o número ultrapassa a quantidade de clientes das duas maiores operadoras de planos de saúde do país juntas (Koike, 2018).

Essas economias já não podem mais ser consideradas como marginais, dada a capacidade de relação íntima com a heterogeneidade metropolitana que articula diferentes repertórios de emprego e de proteção até o comércio ilegal. Isto, num continuum que, em termos neoliberais, organiza-se de modo segmentado revelando o dilema das cidades sobre a simultânea visibilização e invisibilização da função produtivas dessas economias neoliberais desde baixo (Gago, 2018).

Recebido para publicação em 27 de março de 2019 Aceito em 11 de dezembro de 2020

\section{REFERÊNCIAS}

AGUIRRE, A. C; VALDERRAMA, I. I. Políticas sociales, modelo de desarrollo y subjetividad de grupos vulnerables em Chile. Revista del CLAD Reforma y Democracia, 61, p. 209-234, fev. 2015.

ARAUJO, K; MARTUCCELLI, D. La inconsistencia posicional: Unnuevo concepto sobre la estratificación social. Revista Cepal, 103, p. 165-178, abr. 2011.

BRAGA, J. C; DE PAULA, S. G. Capitalismo e Pensamento econômico: a questão da saúde. In: BRAGA, J. C.; DE PAULA, S. G. Saúde e previdência: estudos de política social. São Paulo:Cebes: Hucitec, 1981. p. 1-38.

COHN, A. Desigualdade, Desenvolvimento Social e Políticas Sociais no Brasil. Cadernos Cedec, 57, p. 1-43, ago. 1996.
COHN, A. O jogo de varetas e a desconstrução da cidadania. Plataforma Política Social, 2016. Disponível em: http:// plataformapoliticasocial.com.br/o-jogo-de-varetas-e-adesconstrucao-da-cidadania/. Acesso em 02.11. 2020.

COHN, Amélia. Caminhos da reforma sanitária, revisitado. Estud. av. vol.32 no.93 São Paulo,p. 225-241,ago. 2018.

DARDOT, P; LAVAL, C. A nova razão do mundo: Ensaio sobre a sociedade neoliberal. São Paulo: Boitempo, 2016. 416p.

DAS, V; POOLE, D. Anthropology in the margins of the state, Santa Fé, School of American Research Press, 2004. p. $225-252$.

FASSIN, D. La vie. Mode d'emploi critique, Seuil, Paris, 2018.

FELTRAN, G. O Valor dos pobres. Caderno CRH, 27 (72), p. 495-512, set./dez. 2014.

GAGO, V. A razão neoliberal: economias barrocas e pragmática popular. São Paulo: Elefante, 2018.

GEORGES, I. P. H; SANTOS, Y. G. As 'novas' políticas sociais brasileiras na saúde e na assistência: Produção local do serviço e relações de gênero. Belo Horizonte, Brasil: Fino Traço. 2016. 356p.

IANNI, A. M. Z. Mudanças sociais contemporâneas e saúde: Um estudo sobre teoria social e saúde pública no Brasil. 2012. 186p.Tese (Livre Docência em Saúde Pública). Faculdade de Saúde Pública da Universidade de São Paulo.

IANNI, A.et al. Pensamiento social en salud: un análisis crítico de las obras clásicas del campo de la Salud Pública en Brasil. Rev. Guillermo de Ockham, 15(2), In press, p. 107-117, jun./dez. 2017.

JURCA, R. L. Individualização social, assistência médica privada e consumo na periferia de São Paulo. 2018. 227p. Tese (Doutorado em Saúde Pública) - Programa de PósGraduação em Saúde Pública da Universidade de São Paulo - USP.

Cidade, trabalho e estado de exceção: entrevista com Cibele Saliba Rizek. Áskesis v.8 n.1, p. 83-92, jan./jun. 2019.

KOIKE, B. Um cartão pré-pago só para gastos com saúde. Empresas. Valor Econômico, São Paulo, 28 de setembro de 2018.

KOWARICK, L. Capitalismo e Marginalidade na América Latina. Rio de Janeiro, Brasil: Paz e Terra. 1975. 188p.

. A espoliação urbana (2 ed.). Rio de Janeiro, Brasil: Paz e Terra.1993. 207p.

LAUTIER, B.O governo moral dos pobres e a despolitizacão das políticas públicas na América Latina, Caderno CRH, 27 (72), p.463-477, set./dez. 2014.

LAVINAS, L. A financeirização da política social: o caso brasileiro. Forthcoming at Politika, n. 2, July 2015, Rio de Janeiro, Fundação João Mangabeira em colaboração com Humboldt-Viadrina Governance Platform, p.35-51. 2015

. The Takeover of Social Policy by Financialization: The Brazilian Paradox. Nova York: Palgrave Macmillan, 2017.

LIMA, L. L'expertise sur autrui comme nouveau mode de régulation de la protection sociale. Principes et dispositifs. 2010. Disponível em: https://halshs.archives-ouvertes.fr halshs-00699634/document. Acesso em 25.05.2018.

LOTTA, Gabriela. Estilos de implementação: ampliando o olhar para a análise de políticas públicas. Comunicacão oral, ENAPG ENCONTRO NACIONAL DE ADMINISTRAÇÃO PÚBLICA E GOVERNO. 2008

MARCUS, G. E. Multi-sited Ethnography: Five or Six 
Things I Know About It Now. In: COLEMAN, S.,\& HELLERMANN, P. V. (eds.) Multi-Sited Ethnography: Problems and Possibilities in the Translocation of Research Methods. New York and Abingdon: Routledge. 2011.p. 2653.

MARQUES, E.;BARBOSA, R. J.;PRATES, I. Transformações socioeconómicas e grupos sociais. In: MARQUES, E. (Org.) A metrópole de São Paulo no século XXI: espaços, heterogeneidades e desigualdades. São Paulo: Editora Unesp, 2015. p. 21-43.

MARTUCCELLI, D. Cambio de rumbo: La sociedad a escala del individuo. Santiago, Chile: LOM Ediciones. 2007. 240p.

MINISTÉRIO DA SAÚDE. Secretária Executiva. Programa Agentes Comunitários de Saúde. Brasília-DF. 2001. 40p.

As Cartas de Promoção da Saúde. Brasília: Ministério da Saúde, Secretaria de Políticas de Saúde. 2002. 56p.

MISSE, M. As ligações perigosas: mercado informal ilegal, narcotráfico e violência no Rio, Contemporaneidade e Educação, Salvador, v. 1, n. 2, p. 93-116, jun./out. 2011.

OLIVEIRA, J. A; TEIXEIRA, S. M. F.(Im)previdência social: 60 anos de história da Previdência Social no Brasil. Petrópolis: Vozes: Abrasco. 1986. 356p.

OLIVEIRA, J. A. Reformas e reformismo: "democracia progressiva" e políticas sociais (ou "Para uma teoria política da Reforma Sanitária"). Cadernos de Saúde Pública, Rio de Janeiro, v. 4, n. 3, p. 360-387, out./dez. 1987

OLIVEIRA, F. Crítica à razão dualista: o ornitorrinco. São Paulo: Boitempo, 2013. 152p.

Brasil: Uma biografia não autorizada. São Paulo, Brasil: Boitempo, 2018. 174p.

PAOLI, M. C. O mundo do indistinto: sobre gestão, violência e política. In: OLIVEIRA, F; RIZEK, C. S. (Orgs.) A era da indeterminação. São Paulo: Boitempo, 2007. p. 221-256.

POSTONE, M. Tempo, trabalho e dominação social: Uma reinterpretação da teoria crítica de Marx. São Paulo, Brasil: Boitempo. 2014. 483p.

RIZEK, C. S. Verde amarelo azul e branco: o fetiche de uma mercadoria ou seu segredo. In: OLIVEIRA, Francisco; BRAGA, R., \& RIZEK, C. S. (Orgs.). Hegemonia às avessas. São Paulo, Boitempo Editorial, 2010. p. 215-236.
Trabalho, moradia e cidade: Zonas de indiferenciação?. Revista Brasileira de Ciências Sociais, 27 (78), p. 41-49, jul./fev. 2012.

. Políticas Sociais e Políticas de Cultura: territórios e privatizacões cruzadas. Revista Brasileira de Estudos Urbanos e Regionais, Recife, v. 15, p.199-209. Nov. 2013.

. Faces do lulismo: Políticas de cultura e cotidiano na periferia de São Paulo. In: SINGER, A;LOUREIRO, I. (Orgs.) As contradições do lulismo: A que ponto chegamos?. São Paulo, Brasil: Boitempo. 2016a. p. 185-219.

Um balanço de pesquisa: 10 anos na zona leste e um social reconfigurado. Cidades, São Paulo, Grupo de Estudos Urbanos, v. 13, n. 22, p. 94-140, 2016b.

SANTOS, M. Espaço e Método. 1a edição [1985], São Paulo, Brasil: Edusp. 2014. 120p.

SESTELO, J. A. F. et al. A financeirização das políticas sociais e da saúde no Brasil do século XXI: elementos para uma aproximação inicial. Economia e Sociedade, Campinas, v. 26, Nủmero Especial, p. 1097-1126, dez. 2017.

SOUZA, L. E. P. F. Saúde, desenvolvimento e inovação: uma contribuição da teoria crítica da tecnologia ao debate. Cadernos Saúde Pública, Rio de Janeiro, v. 32 Supl. 2, set./ jan. 2016.

TEIXEIRA, S.F. Reflexões teóricas sobre democracia e Reforma Sanitária. In. Teixeira, S.F. (Org.). Reforma sanitária: em busca de uma teoria. São Paulo: Cortez,1989. p. 17-45.

(Org.). Estado y politicas sociales en América Latina. México, DF: UAM,p. 293-311. 1992.

TELLES, V. S. Sociedade civil e a construção de espaços públicos. In: DAGINO, E. (Org.) Anos 90: política e sociedade no Brasil, São Paulo, Brasil: Brasiliense, 1994. p. 43-53.

VASCONCELOS, I. F. G. G.; ALVES, M. A.; PESQUEUX, Y. Responsabilidade social corporativa e desenvolvimento sustentável: olhares habermasianos. Revista de Administração de Empresas, São Paulo, v. 52, n. 2, p. 148152, 2012. 


\section{NEOLIBERALISM AND INDIVIDUALIZATION IN HEALTH POLICIES IN THE SOUTHERN PERIPHERY OF SÃO PAULO}

\author{
Ricardo de Lima Jurca
}

This article aims to understand the expansion of the public and private health segment for the management of a peripheral territory of the South Zone of the city of São Paulo. This management is based on mediations between the State and users of public health services. In addition to the users interviewed, they participated in the research, social leaders and community social agents of the primary health care program, Family Health Strategy (ESF - Estratégia Saúde da Família). The proposed questions can contribute to identifying and rethinking demand production in social networks of users with access to public and private health services in the region and in the expansion of the social management interface of the health program with private health care in the outskirts of Sao Paulo. The reports show the dynamic relationship between practices, actions and the emergence of the individualization process of the Brazilian social policies.

KEYwORDS: Individualization. Healthcare services. Periphery. Neoliberalism. Public-health.

\section{NÉOLIBÉRALISME ET INDIVIDUALISATION DANS LES POLITIQUES DE SANTÉ DANS LA PÉRIPHÉRIE SUD DE SÃO PAULO}

\author{
Ricardo de Lima Jurca
}

Cet article vise à comprendre l'expansion du segment de la santé publique et privée dans le cadre de la gestion de la population d'un territoire périphérique de la zone sud de la ville de Sao Paulo. Cette gestion est basée sur des médiations entre l'État et les utilisateurs des services de santé publique. Ces derniers ont été interrogés ainsi que des leaders sociaux et des agents du programme de soins de santé primaires dénommé Stratégie de Santé de la Famille (ESF - Estratégia Saúde da Família). Les questions posées peuvent contribuer à identifier et à repenser la production de la demande dans les réseaux sociaux d'utilisateurs ayant accès aux services de santé publics et privés de la région, ainsi qu'à l'extension de l'interface de gestion sociale du programme de santé avec les soins de santé privés en périphérie de Sao Paulo. Les rapports montrent la relation dynamique entre les pratiques, les actions et l'émergence du processus d'individualisation des politiques sociales brésiliennes.

Mots-cLés: Individualisation. Services de santé. Périphérie. Néolibéralisme. Santé publique. 
